\title{
A Polarographic Method for Following the Rates of Cholinesterase-Catalyzed Hydrolyses of Acetylthiocholine ${ }^{1}$
}

\author{
THOMAS H. RIDGWAY ${ }^{2}$ AND HARRY B. MARK, JR. \\ From The Department of Chemistry, The Uninersity of Michigan, \\ Ann Arbor, Michigan
}

Received February 11, 1965

In the past few years there has been considerable interest in the kinetic effects of certain species, such as Mylaxim and THA (9-amino1,2,3,4-tetrahydroaminoacridine) (1), which act as inhibitors in the acetylcholinesterase-catalyzed hydrolysis of acetylcholine. Both compounds are essentially associated (completely inhibit enzyme activity) with the enzyme in less than a few minutes ( 2 to $4 \mathrm{~min}$ ). As available assay methods are incapable of following the rates of such rapid reactions, it was of considerable interest to develop a simple rapid technique for these studies.

The kinetic-based method for mcasurement of acetylcholinesterase activity for inhibition studies is essentially a problem in products analyses, which, under normal conditions, are acetic acid and choline. As a sensitive analytical method for the alcoholic $\mathrm{OH}$ group of the choline molecule is not available, previous methods for following the hydrolysis rates have monitored the rate of production of the protons generated in the reaction. All of these methods are unsuitable for following fast reactions, however. The Warburg manometric method (2), while being the standard method of determining the enzyme activity, is inherently slow in response and limits the choice of medium to a bicarbonate buffer. Titrimetric methods, employing a pH-Stat, such as the methods of Wilson (3) and Main and Dauterman (4), require the use of unbuffered media and are extremely slow because of the very long response time of the glass electrode and the mechanical servo system controlling the addition of $\mathrm{NaOH}$ (specially designed $\mathrm{pH}$ stats, however, are available which have response times of less than $10 \mathrm{sec}$ ). Volume

'Work supported in part by grunts from the U. S. Army Research OfficeDurham, Contract \#DA-31-124-ARO-D-284, and the Horace H. Rackham School of Graduate Studies of the University of Michigan.

${ }^{2}$ Participant in the University of Michigan Undergraduate Research Program. 
changes on tritration further complicate this method. Although the method of Einsel et al. (5) solves the rolume change problem of the above methods by coulometrically titrating the $\mathrm{H}^{+}$, the response time of this technique was reported to be very slow. Reliable measurements could be made only at 4-min intervals.

The inherent difficulties in the methods which monitor the rate of proton formation have led investigators to alternate methods of analysis using artificial substrates. One of the most promising approaches has been to employ the thio ester analog, acetylthiocholine:

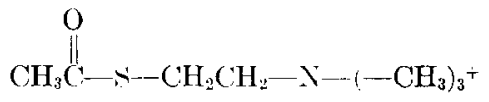

as the substrate. This approach is possible as the thio ester appears to possess almost identical characteristics and chemical properties as the oxy ester with respect to its reaction with cholinesterase (6). [It should be noted, however that this similarity is not general. When assayed against $\mathrm{AchE}$, the acetylthiocholine is hydrolyzed at a much faster rate than acetylcholine (7) ]. The most suitable of the methods devised for the thio ester hydrolysis is that of Ellman of al. (6), which employs the very fast reaction of product - $\mathrm{SH}$ group of thiocholine with $5,5^{\prime}$-dithiobis-2-nitrobenzoale to form a colored species, o-thio-2-nitrobenzoate, with a large extinction coefficient at $412 \mathrm{~m} \mu$. The rate of the hydrolysis is conveniently followed by measuring the rate of formation of the colored species. This method allows a free choice of buffer. Although this method can be used for rapid reactions, it does suffer from the disadvantage of interference by other colored species and from the fact that the wavclength employed for monitoring the reaction docs not correspond to a peak, but lies on a slope of the adkorption eurve which limits the accuracy.

Fiserova-Bergerova (8) has reported that thiocholine exhibits a welldefined polarographic wave. Thus, it is possible that polarography would be an accurate and simple method of following the rapid reaction of this system. This paper describes the technique devised employing polarographic monitoring of the reaction, compares the results obtained with those obtained spectrophotometrically, and diseusses the aceuracy and precision of the method.

\section{METHODS}

The acetylthiocholine (as the iodide salt) and acetylcholinestcrase were obtained from bovine erythrocytes and purchased from Sigma Chemical Co., St. Louis, Mo. The acetylthiocholine, S, solutions were $0.035 \mathrm{M}$ and maintained at $\mathrm{pH} 7$ by means of a phosphate buffer, $B$, 
which had an ionic strength of 0.05 . The enzyme, $E$, solutions were prepared as 100 units/ce with the same buffer. Both these solutions were deaerated with $\mathrm{N}_{2}$ and stored frozen. The 5,5'-dithiobis-2-nitrobenzoate was purchased from Aldrich Chemical Company, Milwaukee, Wis. Solutions of this compound were prepared by dissolving $99.7 \mathrm{mg}$ in $25 \mathrm{ml}$ of the buffer. Neostigmine bromide, employed as an inhibitor, $I$, was purchased from Mann Laboratories, New York, and was prepared as a $0.001 M$ solution in the deaerated buffer. The phosphate buffer was prepared from $\mathrm{KH}_{2} \mathrm{PO}_{4}$ (Baker Analyzed Reagent) and $\mathrm{NaOH}$ (Acculate) in triply distilled deaerated water. All solutions were stored under $\mathrm{N}_{2}$.

In general, the rates of the hydrolysis reaction were followed by applying a constant -0.20 volt vs. saturated calomel electrode (S.C.E.) to the dropping mercury electrode (D.M.E.) in the polarographic cell and recording the increase in the anodic (oxidizing) current as a function of time. These rate curves and also polarograms of the system were obtained with a Sargent model XV recording polarograph. The D.M.E. used in these experiments had a drop time of $2.71 \mathrm{sec}$ at a height of 61.3 $\mathrm{cm}$ of mercury in the buffer solution with -0.20 volt vs S.C.E. applied potential. Under these conditions the outflow of mercury was $1.63 \mathrm{mg} /$ sec. The temperature of the polarograph cell was maintained at $25^{\circ} \mathrm{C} \pm$ $0.1^{\circ}$ by means of a thermostated water bath. All solutions were brought to thermal equilibrium before a measurement was started. In general, $5 \mathrm{ml}$ of the buffer solution was added to the polarograph cell and the other components then added. In the rate measurements, the enzyme was added last and stirred briefly with $\mathrm{N}_{2}$, and the rate curve was then recorded. All potentials reported were measured with reference to a S.C.E. which made electrical contact with the solution in the polarographic cell by means of an agar-agar $\mathrm{KCl}$ salt bridge.

All spectrophotometric measurements werc made with a Bcckman DU spectrophotometer.

Correlation of rate data obtained polarographically with that obtained spectrophotometrically by the method of Ellman (6) was carried out under three different conditions in order to minimize the possibility of procedural errors: (1) the constituents of the reaction mixture were $90 \mathrm{ml}$ of $B, 7.2 \mathrm{ml}$ of $S$, and $1.8 \mathrm{ml}$ of $E$. $\Lambda$ t 5 -min intervals, $0.500-\mathrm{ml}$ aliquots of this solution were taken and added to $1.0 \mathrm{ml}$ of $I$ (to stop the reaction), and diluted to $10 \mathrm{ml}$ with $B$. (Note that the correlation study was carried out by stopping the reaction and analyzing the product by both methods. This was done so that an exact comparison of the two methods could be made. Normally the reaction rate is recorded continuously as the reaction proceeds in the polarograph cell.) (2) The 
reaction solution consisted of $10 \mathrm{ml}$ of $B, 0.80 \mathrm{ml}$ of $S$, and $0.80 \mathrm{ml}$ of $E$. At 200 -sec intervals, $0.500-\mathrm{ml}$ aliquots were added to $0.50 \mathrm{ml}$ of $I$ and diluted to $10 \mathrm{ml}$. Portions of this solution were analyzed by both techniques. (3) The solution consisted of $10 \mathrm{ml}$ of $B, 0.8 \mathrm{ml}$ of $S$, and $1.20 \mathrm{ml}$ of $E$, and $0.100-\mathrm{ml}$ aliquots were taken at various times (recorded) and treated and analyzed in the same manner as (2).

All rate data reported in this paper was analyzed statistically by the method of Bennett and Franklin (9) and straight-line plots were drawn by means of a conventional least-square linear regression treatment of the data.

\section{RESULTS}

Figure 1 shows the charicteristics of the polarograms obtained for this system. Curve 0 of Fig. 1 represents the background current obtained for the phosphate buffer alone. Curve 1 represents the wave obtained for a $5.5 \times 10^{-3} \mathrm{M}$ acetylthiocholine iodide-buffer solution. Note that a wave appears at approximately -0.1 volt vs. S.C.E. This wave is probably not a result of the oxidation of the substrate itself, but probably represents the oxidation of mercury in the presence of iodide ion to form a mercury-iodide compound. This conclusion was substantiated by measuring several different polarograms containing different concentrations of substrate and then repeating the same measurements, with buffer solutions containing only KI in the same concentration as $S$. The waves were essentially identical. Also, FiserovaBergerova (8) reported that no wave was observed at this potential when salts other than the iodide salt were used. Curves $2-8$ of Fig. 1 represent the polarograms obtained at successive 10-min time intervals following addition of 40 units of the cnzyme to the same solution corresponding to curve 1 . Note that a new wave appears at more negative potentials which increases with time. The half-wave potential, $E_{1 / \text {, }}$, is -0.405 volt vs. S.C.E. This wave (and half-wave potential) corresponds almost exactly with that reported by Fiserova-Bergerova (8) for thiocholine, $P$, which is the product of the enzyme-catalyzed hydrolysis. Figure 1 shows that this polarographic wave is well defined in this system and by monitoring the current as a function of time at a constant applied potential, $E_{c}$, of -0.20 volt vs. S.C.E., the rate of production of thiocholine is easily followed.

The electrochemical characteristics, such as $E_{1 / 2}$, electrocapillary curves (10), mercury height (11) dependence, and wave shape are almost identical to those reported by Stricks and Kolthoff (12) and Tachi and Koide (13) for the anodic wave of a similar sulfhydryl-containing compound, glutathione, under similar conditions. They concluded that 


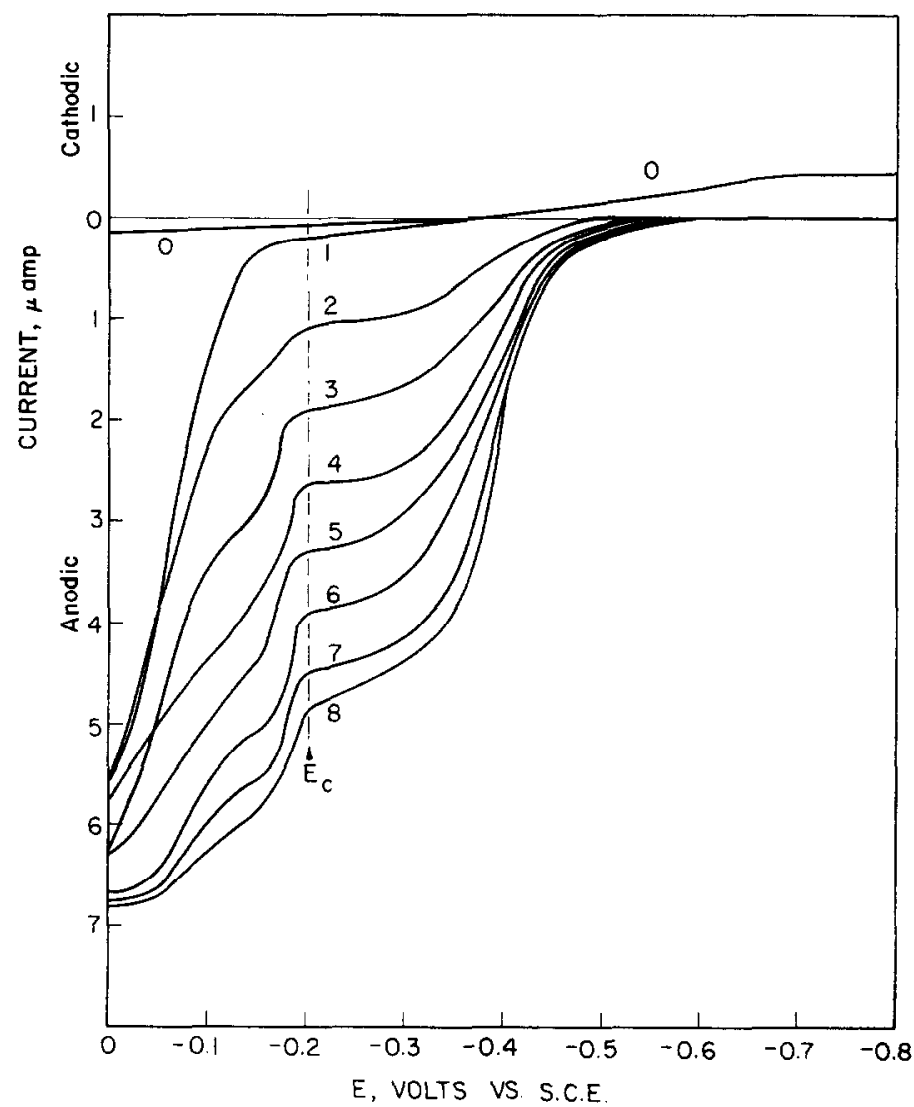

FIG. 1. Polarographic characteristics of the acetylthiocholine-cholinesterase system at $25^{\circ} \mathrm{C} \pm 0.1^{\circ}$ and $\mathrm{pH} 7.0$ (phosphate buffer; ionic strength 0.05 ): (curve 0 ) background wave of phosphate buffer; (curve 1) $5.5 \times 10^{-3} M$ acetylthiocholine in buffer; (curves 28 ) same as curve 1, except 40 units of cholinesterase added and polarograms run at 10 -min intervals.

the wave corresponded to mercury oxidation in the presence of the sulfhydryl group to form a complex of the type, $(\mathrm{R} \longrightarrow \mathrm{S})_{2} \mathrm{Hg}$.

The commercial enzyme preparation used in this study was found to contain some polarographically active component or group which was not, however, associated with the active sites of the enzyme itself. This "material" exhibits a poorly defined cathodic double wave beginning at approximately 0 volt vs. S.C.E. The height of this cathodic wave was directly proportional to concentration of the enzyme, and its height decreased linearly with time when the enzyme solution was electrolyzed at a constant voltage of -0.25 volt vs. S.C.E. (on the second plateau). 
The rate of decrease of this wave was found to be $5.5 \times 10^{-3} \mu$ amp $\mathrm{ml} / \mathrm{min} /$ unit concentration enzyme, which results in a finite error in determining the rate of production of the thiocholine during slow hydrolysis reactions, as shown in Table 1 . As the measured current at -0.20 volt will be the sum of this cathodic current and the anodic thiocholine current, this material results in an error which is easily circumvented.

TABLE 1

Comparison of the Polarographic and Spectrophotometric (6) Methods

\begin{tabular}{|c|c|c|c|c|c|}
\hline Run & $\begin{array}{l}\text { Sam- } \\
\text { ples }\end{array}$ & $\begin{array}{l}\text { Ellman }(6) \text { method } \\
\frac{d[\text { thiocholine] }}{d t} \times 10^{-6} \text {, } \\
\text { mole/liter } / \mathrm{min} / \text { unit } \\
\text { enzyme concn. }\end{array}$ & $\begin{array}{l}\text { Polarographic } \\
\left(\frac{d\left({ }^{i} d\right)}{i t}\right)_{-0.2 v o l t} \times 10^{-2}, \\
\mu a m p / 1 \text { iter } / \min / \text { unit } \\
\text { enzyme conen. }\end{array}$ & 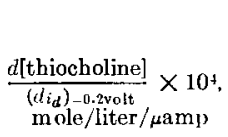 & $\begin{array}{l}\text { St. dev. } \\
\text { moie } / \text { liter } / \mu \mathrm{amp}\end{array}$ \\
\hline $1^{a}$ & 9 & 0.912 & 5.57 & 1.646 & 0.0451 \\
\hline $2^{b}$ & 9 & 0.925 & 5.58 & 1.663 & 0.0312 \\
\hline $3^{a}$ & 9 & 0.925 & 5.58 & 1.671 & 0.0793 \\
\hline $3^{c}$ & 9 & 0.925 & 5.72 & 1.715 & 0.0196 \\
\hline
\end{tabular}

a Corrected algebraically for $\left(d_{i} / d l\right)_{-0.2 v o l t}$ of the electruactive enzyme material (see text).

${ }^{b}$ Enzyme stock solution pre-electrolyzed (see text).

- Uncorrected data.

One can also simply correct for the small change in the current resulting from the electrolysis of this "material," as its time rate of change is linear and can be subtracted from the total over-all current change to give the time rate of change of current resulting from the oxidation of thiocholine. Electrolysis of the stock enzyme solution (containing the buffer) at -0.25 volt vs. S.C.E. for a period of $1.5 \mathrm{hr}$ using a D.M.E. completely removes this polarographically active "material" without affecting the enzyme activity (see Table 1). This pretreatment step is a more sure way of circumventing this source of error and could be accomplished much fastcr by using a macro stirred $\mathrm{Hg}$ pool electrode during the constant potential electrolysis. Table 1 shows that the pretreatment of the enzyme solution and algebraic correction yield the same numerical results for the rate of hydrolysis. Note that the correction or removal of this "material" is necessary only when very slow hydrolysis reactions are being studied, as the rate of change with time of this wave is very small when the D.M.E. is used.

In the experiments performed to compare the polarographic method with the spectrophotometric method of Ellman (6), it was found that rate of change of concentration of thiocholine, $d[$ thiocholine] $/ d t$, on hydrolysis as measured by the method of Ellman (6) was directly 
proportional to the rate of change of the diffusion current at -0.20 volt, $\left(d_{i_{d}} / d t\right)_{-0.20 \text { vol } t}$, for all three different solution conditions tried (9 runs were made for each solution condition) as shown in Table 1. This is further evidence that the anodic wave observed corresponds to thiocholine oxidation.

The value of the Michaelis-Menten constant, $K_{m}(4,6)$, for the cholinesterase-catalyzed hydrolysis of acethylthiocholine calculated from rate data obtained by the polarographic method of this paper was $3.23 \times 10^{-4} \mathrm{~mole} / \mathrm{liter}$. This value compares reasonably well with the value of $1.40 \times 10^{-4}$ mole/liter reported by Ellman (6), which was calculated from rate data of Ellman (6) obtained by the spectrophotometric method. Table 2, which compares the $K_{m}$ values obtained for several different substrates, shows that the difference between the $K_{m}$ values measured polarographically and spectrophotometrically for acetylthiocholine is within the range of disagreement (degree of accuracy) obtained by other investigators for the $K_{m}$ of the acethylcholine hydrolysis.

TABLE 2

Values of $K_{m}$ for the Cholinesterase-Catalyzed Hydrolysis of Different Substrates

\begin{tabular}{ccc}
\hline Acetylcholine & Acetylthiocholine & Phenyl acetate \\
\hline $1.50^{a} \times 10^{-4}$ & $1.40^{b} \times 10^{-4}$ & $6.67^{a} \times 10^{-4}$ \\
$2.00^{b} \times 10^{-4}$ & $3.23^{d} \times 10^{-4}$ & \\
$5.50^{c} \times 10^{-4}$ & & \\
\hline
\end{tabular}

${ }^{a}$ Main and Dauterman (4).

${ }^{b}$ Ellman (6).

c Feinsilver et al. (1).

$d$ This study.

Study of the Kinetics of Inhibition by Neostigmine Bromide. A few experiments were performed which studied the kinetics of the inhibition of the cholinesterase catalyzed hydrolysis of acetylthiocholine by neostigmine bromide. The experiments illustrate the applicability of the polarographic method for studying these types of reaction. In these experiments, the inhibitor was added to the enzyme-substrate systems ( $[E]=3$ units $/ \mathrm{ml},[S]=3 \times 10^{-3} M$ ), mixed, and the rate of production of thiocholine followed polarographically [according to Goldstein (14) this order of addition of inhibitor leads to competitive inhibition]. A value for $K_{m}$ [related to the equilibrium constant, $K_{l}$, when steadystate measurements are taken, by the expression $K_{m}=\left(K_{I} / 1\right)+\left(k_{3}\right)$ $k_{4}$ ), where $k_{3}$ and $k_{4}$ are rate constants for the subsequent reactions of 
the dimethylcarbamyl-enzyme derivative formed and where $k_{3}>>k_{4}$ $(15,16)]$ for an inhibitor reaction, under competitive conditions, can be calculated according to Wilson (17) from the expression:

$$
K_{m}=\frac{[I]}{\left[\left(V^{0} / V\right)-1\right]\left[1+\left([S] / K_{m}\right)\right]}
$$

where [I] is inhibitor concentration $\left(10^{-\tau} M\right.$ in this experiment), $V^{o}$ is the uninhibited reaction velocity, and $V$ is the equilibrium inhibited velocity. A value of $K_{m}$ of $3.6 \times 10^{-7} \mathrm{M}$ with a standard deviation of $0.6 \times 10^{-7} M$ was calculated from the data of 5 runs. This value is comparable to that reported by Wilson (17), $K_{m i}=0.93 \times 10^{-7} \mathrm{M}$, which was obtained under noncompetitive conditions (14) and at an ionic strength of 0.02 and $\mathrm{pH}$ of 7.2 , and that reported by Augustinsson and Nachmansohn (18), $K_{m}=1.6 \times 10^{-i} M$, obtained under competitive conditions.

The rate of association, $K_{1}$, of neostigmine with the cholinesterase was calculated also by two different methods under two different inhibitor concentration conditions.

Under exactly the same solution conditions cmployed above in the $K_{I}$ measurements, $K_{1}$ can be calculated for a competitive reaction, according to Wilson (17), from the expression:

$$
K_{1}=\frac{2.3\left(V-V^{0}\right)}{I t_{1} V^{0}} \log \frac{\left(V_{1}-V\right)}{\left(V^{0}-V\right)}
$$

where $V_{1}$ is the reaction velocity at any time, $t_{1}$, before equilibrium and the other symbols have the same meaning as above. The value of $t_{1}$, employed in this experiment was $1 \mathrm{~min}$. A value of $K_{1}=6.0 \times 10^{+}$ $\sec ^{-1} M^{-1}$ with a standard deviation of $0.4 \times 10^{4} \mathrm{sec}^{-1} M^{-1}$ was obtained from the data of 5 runs. Wilson (17) obtained a value of $1.2 \times 10^{1}$ sec $^{-1} M^{-1}$ for $K_{1}$ for a reaction run under noncompetitive conditions. Employing conditions which give a much faster rate of inhibition ( $[I]=10^{-4} M,[S]$ and $[I]$ same) and using the expression derived by Main and Dauterman (4) for $K_{1}$ (competitive conditions, also):

$$
K_{\mathrm{I}}=\frac{2.3}{t_{1}\left[K_{m} /\left(K_{m}+[S]\right)\right][I]} \log \frac{\mathrm{V}^{\circ}}{V_{1}}
$$

a value of $K_{1}=5.9 \times 10^{4} \mathrm{sec}^{-1} M^{-1} \pm 0.6 \times 10^{4} \mathrm{sec}^{-1} M^{-1}$ was obtained for 5 runs $\left(t_{1}=1 \mathrm{~min}\right)$. The reaction under these conditions was quite fast. Total inhibition was obtained within $4 \mathrm{~min}$.

\section{DISCUSSION}

It was found that the polarographic method agrees very well with the spectrophotometric method of Ellman (6) with respect to the rate 
of production of thiocholine on the cholinesterase-catalyzed hydrolysis of acetylthiocholine. The major advantage of the polarographic method is its simplicity and ability to follow fast reactions, as demonstrated by the results obtained in this study using large concentrations of the inhibitor, neostigmine bromide, which simulates the rates expected with the fast inhibitors (1). Reliable data on the rate of change of enzyme activity is obtained after a few seconds $(\sim 5$ to $10 \mathrm{sec})$ after addition of the inhibitor to the enzyme-substrate system. This time lapse is a result of the brief mixing period followed by the time required for the solution to become quiescent after mixing after the inhibitor is added. This "dead time" could be reduced substantially by using either a rotated mercury electrode (19) or a mercury-coated platinum electrode (20) employing voltametric conditions (21) which do not require the solution to become quiescent before data can be taken. Further reduction of the "dead time" could be accomplished by using fast mixing techniques, such as the stop-flow system of Chance (22), in conjunction with the stirred-electrolysis conditions of voltametry.

\section{SUMMARY}

A rapid and simple polarographic method for following the rates of the cholinesterase-catalyzed hydrolysis of acetylthiocholine and the rates of inhibition of this hydrolysis is described. This method has the advantage that it can follow quite rapid reactions, as meaningful data can be obtained after 10 sec of mixing of the solutions. The method follows the rate of increase of the anodic polarographic wave of thiocholine produced by the hydrolysis. The validity of the method was determined by comparing the rates of production of thiocholine spectrophotometrically and polarographically. Also the values of $K_{m}$ for the hydrolysis, and $K_{m}$ and $K_{1}$ for the inhibition reaction of neostigmine were determined and compared to values reported in the literature.

\section{REFERENCES}

1. Feinshyer, L., Vocci, F. J., Rimaway, T. H., and Granger, M. M., U. S. Army Chemical Laboratories Technical Report CRDLR 3209, 1964.

2. Nachmansohn, D., and Rothenburg, M., J. Biol. Chem. 155, 197 (1947).

3. Wilson, I. B., J. Biol. Chem. 208, 123 (1954).

4. Main, A. R., and Dauterman, W. C., Nature 198, 551 (1962).

5. Einsel, D. W., Jr., Trunit, H. J., Silver, S. D., Ano Steiner, E. C., Anal. Chem. 28, 108 (1956).

6. Ellman, G. L., Courtiey, K. D., Andres, V.. Jr., and Featherstone, R. M., Biochem. Pharmacol. 7, 88 (1962).

7. Koelle, G. B., J. Pharmacol. Exptl. Therap. 100, 158 (1950).

8. Fiserova-Bergerova, V., Collection Czech. Chem. Commun. 27, 693 (1962). 
9. Bennett, C. A., and Franklin, N. L., "Statistical Analysis in Chemistry and the Chemical Industry." Wiley, New York, 1961.

10. Reilley, C. X., and Stumm, W., in "Progress in Polarography," Vol. I (P. Zuman and I. M. Kolthoff, eds.), Interscience, London, 1962, Chap. V.

11. Zuman, P., "Organic Polarographic Analysis." Macmillan, New York, 1964.

12. Stricks, W. S., ANd Kolthoff, I. M., J. Am. Chem. Soc. 74, 4646 (1952).

13. Tachi, I., and Koine, S., Sh. Mezinarod. Polrrog. Sjezdu Praze, 1st Congr. 1951, Pt. 1, 450-68 (1961).

14. Goldstrin, A., Arch. Biochem. Biophys. 33, 169 (1961).

15. Wilson. 1. B., Hatch, M. A., and Ginsburg, S., J. Biol. Chem. 235, 2312 (1960).

16. Wilson, i. B., Harrison, M. A., and Ginsburg, S., J. Biol. Chem. 236, 1498 (1961).

17. Wilson, I. B., Arch. Intern. Pharmacodyn. 104, No. 2, 204 (1955).

18. Augustinsson, K. B., and Nachmaxsohn, D., J. Biol. Chem. 179, 543 (1949).

19. IEE, T. S., J. Am. Chem. Soc. 74, 5001 (1952).

20. Ramatir, L., Brubaker, R. L., and Enke, C. G., Anal. Chem. 35, 1088 (1963).

21. Remlley, C. N., and Murkay, R. W., in "Treatise on Analytical Chemistry" (I. M. Kolthoff and P. J. Elving, eds.), Part 1, Vol. 4. Interscience, New York, 1963, Chap. 43.

22. Chasce, B, J. Biol. Chem. 151, 533 (1943). 